\title{
Cervical spondylosis as a possible hidden reason beyond delayed phrenic nerve distal motor latency
}

\author{
Rowaida Hamdy Ali, Mai Mohamed Farouk and Salwa Galal Moussa *
}

\begin{abstract}
Background: Cervical spondylosis is a chronic degenerative condition of the cervical spine that can affect the cervical nerve roots. The origin of the phrenic nerve makes it vulnerable to injury. The purpose of this study is to investigate possible subtle phrenic nerve affection in patients with cervical spondylosis using nerve conduction studies (NCS). This study was conducted on 30 patients with cervical spondylosis above C5 and on 30 healthy volunteers. Nerve conduction studies of both phrenic nerves were performed in all cases.

Results: The patients with cervical spondylosis showed a statistically highly significant prolongation of phrenic nerve distal motor latency $(\mathrm{DML})$ than the control group $(P<0.01)$. There was no significant difference regarding amplitude $(P>0.05)$. There was a significant correlation between DML and $X$-ray score $(r<0.05)$.

Conclusions: Cervical spondylosis is an underestimated cause of phrenic nerve delayed DML. There is a correlation between the delay of phrenic nerve DML and the severity of cervical spondylosis.
\end{abstract}

Keywords: Phrenic neuropathy, Phrenic nerve conduction study, Cervical spondylosis

\section{Background}

The diaphragm, the fundamental muscle of respiration, is innervated by the phrenic nerve which originates from the cervical ventral horn of $\mathrm{C} 3-\mathrm{C} 5$ roots, and it is supplied mainly by $\mathrm{C} 4$ [1]. Injury to the phrenic nerve and/or one of its roots may lead to diaphragmatic paralysis (DP) and dysfunction [2]. The spinal level mostly affected in cervical spondylosis is $\mathrm{C} 5-\mathrm{C} 6, \mathrm{C} 6-\mathrm{C} 7$, and C4-C5. Accordingly, the phrenic nerve is vulnerable to compression in cervical spondylosis [3, 4]. Phrenic nerve injury can be evaluated using multiple modalities including esophageal and gastric manometry, phrenic nerve conduction studies (NCS), diaphragmatic electromyography (EMG), or ultrasound [5]. We aimed to investigate possible subtle phrenic nerve injury in patients with cervical spondylosis.

\footnotetext{
*Correspondence: dr_salwa07@yahoo.com

* Correspondence: dr_salwa07@yahoo.com
Physical Medicine, Rheumatology \& Rehabilitation Department, Faculty of Medicine, Ain Shams University, Cairo, Egypt Medicine, Ain Shams University, Cairo, Egypt
}

\section{Methods \\ Patient selection}

This case-control study was conducted on 30 patients suffering from neck pain diagnosed as cervical spondylosis above $\mathrm{C} 5$ by using X-ray cervical spines. Additionally, there are 30 sex- and age-matched healthy volunteers in the control group. Both patients and volunteers were recruited from the physical medicine, rheumatology, and rehabilitation outpatient clinic.

\section{Exclusion criteria}

Patients presenting with a lesion that can possibly affect the phrenic nerve like respiratory disease, diabetes mellitus, peripheral neuropathy, multiple sclerosis, motor neuron disease, Guillain-Barre syndrome, high-level spinal cord injury, sarcoidosis, muscle dystrophy, cardiac and thoracic surgery, trauma, infections (Herpes zoster and Lyme disease), and/or malignancy were excluded from the study.

\section{Springer Open}

(c) The Author(s). 2021 Open Access This article is licensed under a Creative Commons Attribution 4.0 International License, which permits use, sharing, adaptation, distribution and reproduction in any medium or format, as long as you give appropriate credit to the original author(s) and the source, provide a link to the Creative Commons licence, and indicate if changes were made. The images or other third party material in this article are included in the article's Creative Commons licence, unless indicated otherwise in a credit line to the material. If material is not included in the article's Creative Commons licence and your intended use is not permitted by statutory regulation or exceeds the permitted use, you will need to obtain permission directly from the copyright holder. To view a copy of this licence, visit http://creativecommons.org/licenses/by/4.0/. 
This study was submitted to and approved by the FMASU REC ethics committee, FWA 000017585. All participants signed a written consent to participate in this study.

\section{Methodology}

All participants were subjected to a full medical history and thorough clinical examination. Posteroanterior and lateral cervical X-ray films using a grading system of the cervical degenerative index by Ofiram et al. were performed [6]. Cervical spine magnetic resonance imaging (MRI) was performed on patients with grade 3 and grade 4 to exclude cervical disc prolapse. After taking the participants' consent, electrophysiological studies were performed in a quiet room with a constant temperature of $27^{\circ} \mathrm{C}$. The participant was placed in the supine position. The operator was blinded with the status of the subjects as either patients or controls. The study was conducted using a four-channel electromyography instrument (EMG/NCV/EP system topas 230/240 V Schwarzer $\mathrm{GmbH})$. Phrenic NCS were performed bilaterally on the participants with a bipolar stimulating electrode between the sternal and clavicular heads of the sternocleidomastoid muscle just above the clavicle or lateral to the clavicular head. The active electrode (G1) was fixed $5 \mathrm{~cm}$ above the xiphoid process, and the reference electrode (G2) was placed $16 \mathrm{~cm}$ from G1 on the chest margin ipsilateral to the stimulated phrenic nerve [7] (Fig. 1). Phrenic nerve CMAP onset latency (ms) and amplitude $(\mu \mathrm{V})$ were obtained at supramaximal stimulation [7]. The values of phrenic NCS were obtained from the patient group and compared to the corresponding sides in the control group.

\section{Statistical analysis}

Data were calculated and tabulated, and statistical analysis was performed. IBM SPSS statistics (V. 23.0, International Business Machines Corporation, Armonk, NY) was used for data analysis. The following tests were done: comparison between two independent mean groups for parametric data using the Student $t$ test and

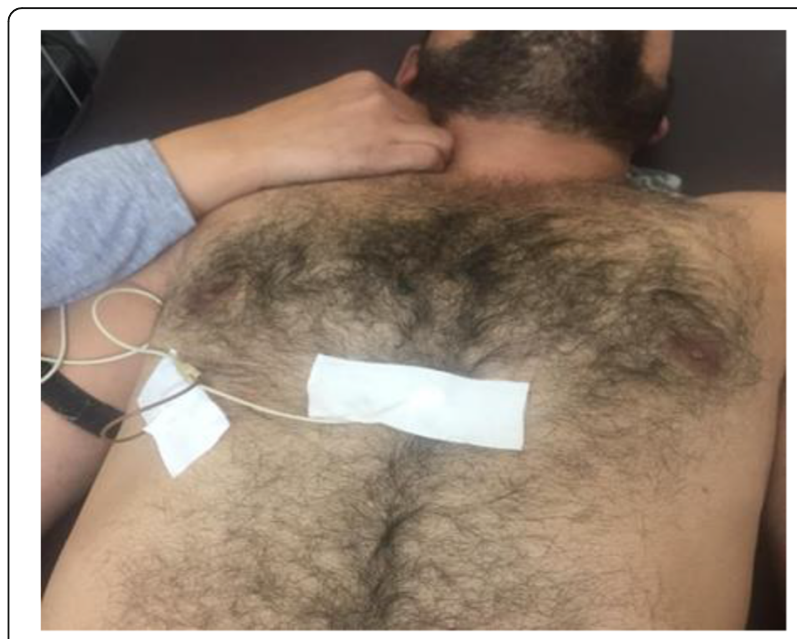

Fig. 1 Application of recording electrodes for phrenic NCS

the Pearson correlation test to study the possible association between two variables among each group for parametric data. The probability of error $P \leq 0.05$ was considered significant while $P \leq 0.001$ was considered highly significant. Sensitivities and specificities of phrenic nerve DML and amplitude were analyzed using the receiver operating characteristic (ROC) curve.

\section{Results}

Our study included 30 patients with a diagnosis of cervical spondylosis with an age range of 38-57 years and were matched with 30 healthy controls with ages ranging from 34 to 55 years. In the patient group, 18 were males $(\mathrm{M}=60 \%)$ and 12 were females $(\mathrm{F}=40 \%)$. In the control group, 19 participants were males $(\mathrm{M}=63.3 \%)$ and 11 were females $(F=36.7 \%)$. The patient and control groups were also matched regarding sex $(P>0.05)$. BMI in the patient group and control group was $27.29 \pm 1.92$ and $26.21 \pm 1.96$, respectively.

The patients with cervical spondylosis showed a statistically highly significant prolongation of phrenic nerve DML on both sides compared to the controls $(P<$ 0.001). Evaluation of phrenic nerve amplitude revealed a

Table 1 Comparison between patients and controls regarding electrophysiological data

\begin{tabular}{rllllll}
\hline Side & $\begin{array}{l}\text { Patients phrenic DML, range } \\
\text { (min-max) }\end{array}$ & Patients, mean \pm SD & $\begin{array}{l}\text { Control phrenic DML, range } \\
\text { (min-max) }\end{array}$ & Controls, mean \pm SD & $\boldsymbol{t}$ & $\boldsymbol{P}$ \\
Rt phrenic & $6.1-9.9$ & $8.05 \pm 1.2$ & $6.1-8.1$ & $7.01 \pm 0.4$ & 4.5 & $0.0001^{* * *}$ \\
Lt phrenic & $6.6-9.8$ & $7.89 \pm 1.06$ & $6.1-8.3$ & $6.99 \pm 0.399$ & 4 \\
Side & $\begin{array}{l}\text { Patients phrenic amplitude, } \\
\text { range (min-max) }\end{array}$ & Patients, mean \pm SD & $\begin{array}{l}\text { Controls phrenic amplitude, } \\
\text { range (min-max) }\end{array}$ & Controls, mean \pm SD & $\boldsymbol{t}$ & $\boldsymbol{P}$ \\
Rt phrenic & $281-543$ & $411.6 \pm 6001^{* * *}$ & & \\
Lt phrenic & $308-564$ & $413.6 \pm 61.61$ & $376-498$ & $426.2 \pm 39.37$ & -1 & 0.15 \\
\hline
\end{tabular}

$t, P: t$ and $P$ values for the Student $t$ test for comparing between the two categories $D M L$ distal motor latency, min minimum, max maximum, $S D$ standard deviation, $R t$ right, $L t$ left

${ }^{* * *}$ Very high statistical significance at $P \leq 0.001$ 
Table 2 The determined cutoff points for different electrophysiological studies

\begin{tabular}{lllllll}
\hline Electrophysiological study & Determined cutoff point & Sensitivity (\%) & Specificity (\%) & PPV (\%) & NPV (\%) & AUC (\%) \\
\hline Phrenic DML & $>7.2 \mathrm{~ms}$ & 71.76 & 68.33 & 69.4 & 70.7 & 76.6 \\
Phrenic amplitude & $<387 \mu \mathrm{V}$ & 40 & 90 & 80 & 60 & 60 \\
\hline
\end{tabular}

$D M L$ distal motor latency, $m s$ millisecond, $\mu v$ microvolt, $P P V$ positive predictive value, NPV negative predictive value, $A U C$ area under the curve, $\%$ percentage

non-significant difference between both groups $(P>$ 0.05) (as shown in Table 1).

ROC curve analysis revealed a good ability of DML to differentiate between healthy and affected phrenic nerve (area under the curve (AUC) 76.6\%) which was more than the amplitude (AUC 60\%). At the individual level, values of phrenic NCS exceeding the cutoff point and normative data obtained from the controls were considered abnormal (shown in Table 2). Only 3 patients (10\%) showed normal DML while 27 patients (90\%) showed delayed value regarding this parameter (Fig. 2). At the same time, 14 patients (46.6\%) showed lower amplitude while 16 of them (53.4\%) revealed average value.

Interestingly, the $\mathrm{X}$-ray score has a highly significant positive correlation with right phrenic nerve DML $(P<$ $0.001)$ and a significant correlation with the left $(P<$ $0.05)$. There was no significant difference between the amplitudes of CMAP of Rt and Lt phrenic nerves $(P<$ $0.05)$, and there was no significant correlation between the duration of neck pain and both phrenic DML and CMAP amplitude on both sides (as shown in Table 3).

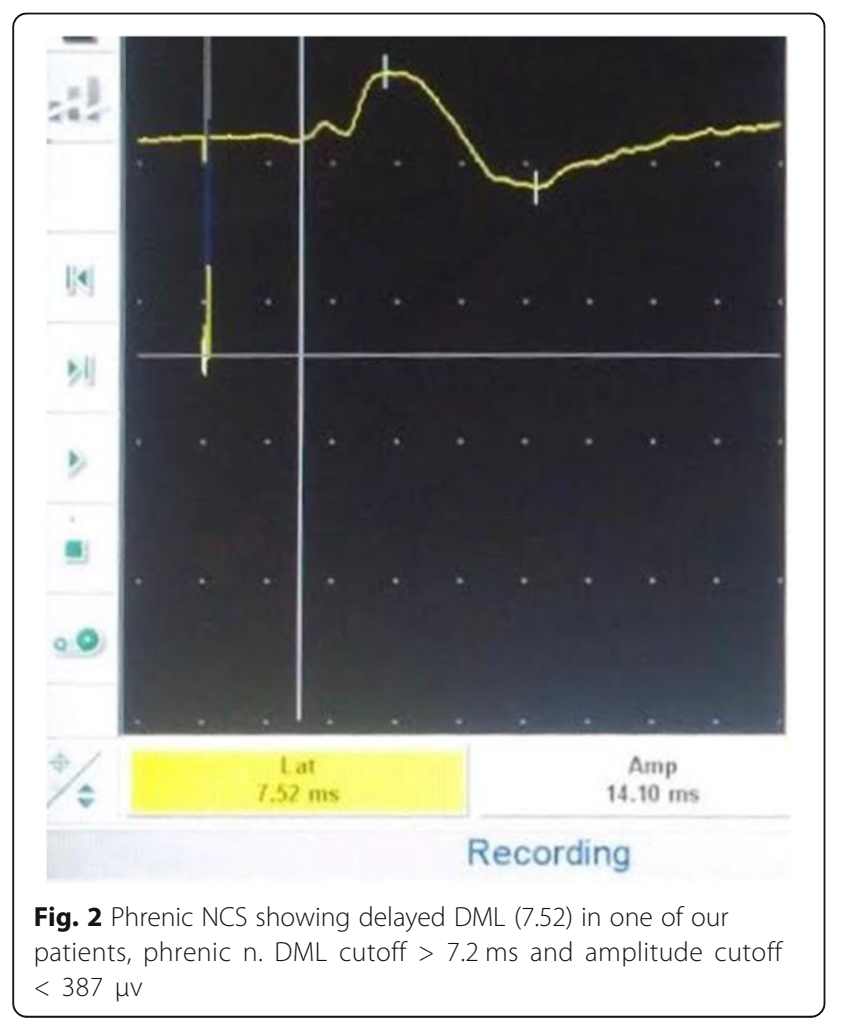

\section{Discussion}

Though diaphragmatic dysfunction due to phrenic nerve compression by cervical spondylosis (at C3, C4, and/or C5) is not a common cause, further investigation is required to be excluded [8]. Phrenic nerve neuropathy usually has non-specific signs and symptoms, so high suspicion should be raised especially in unilateral DP when a patient is asymptomatic at rest but has dyspnea on exertion [9]. Supporting this, Sagoliocco et al. revealed a dramatic unilateral phrenic nerve involvement in the absence of clinical and laboratory evidence of diaphragmatic weakness [10].

The significant delay of phrenic nerve DML in the patient group with cervical spondylosis compared to the control group could be a sign of demyelination which could be attributed to hypoxia caused by compression affecting myelination and conduction of impulses [11]. Noticeably, we did not record a significant reduction in the amplitude of phrenic nerve CMAP of the patient group. It is thought that this could be due to the axons of the phrenic nerve being unaffected by the compression and hypoxia caused by spondylosis. Higher levels of compression are known to occur with severe disc prolapse and myelopathies [12, 13].

Our study reported a significant positive correlation between DML and X-ray score where $100 \%$ of patients with grade 4 had delayed DML. Sachin et al. supported the same concept and showed that DML is not affected in cervical radiculopathies unless there is extreme demyelination of axons [13]. The patients with high X-ray scores in our study were found to have severe phrenic demyelination.

In the current research, we reported a non-significant negative correlation between phrenic nerve CMAP amplitude and X-ray score in the patient group. This could be explained as a tendency of an axonal lesion to the phrenic nerve roots which similarly occurs with severe disc prolapse and myelopathies [12-14]. Additionally, a non-significant correlation between values of phrenic NCS and neck pain duration could be recorded which may indicate that phrenic nerve DML is mostly affected by the grade of cervical spondylosis and not the duration itself.

\section{Conclusions}

Cervical spondylosis is an underestimated cause of phrenic nerve delayed DML. There is a correlation 
Table 3 Correlation between phrenic DML and some parameters

\begin{tabular}{|c|c|c|c|c|c|c|c|c|}
\hline \multirow[t]{2}{*}{ Parameter } & \multicolumn{2}{|c|}{ Rt phrenic DML } & \multicolumn{2}{|c|}{ Lt phrenic DML } & \multicolumn{2}{|c|}{ Rt phrenic amplitude } & \multicolumn{2}{|c|}{ Lt phrenic amplitude } \\
\hline & $r$ & $P$ & $r$ & $P$ & $r$ & $P$ & $r$ & $P$ \\
\hline X-ray score & 0.56 & $0.0001^{* * *}$ & 0.41 & 0.02 & -0.54 & $0.0001^{* * *}$ & -0.6 & $0.0001^{* * *}$ \\
\hline Neck pain duration & 0.12 & 0.52 & 0.02 & 0.9 & -0.21 & 0.2 & -0.28 & 0.13 \\
\hline
\end{tabular}

$r$ Spearman coefficient, $R t$ right, $L t$ left, $D M L$ distal motor latency

${ }^{* * *}$ Statistical very high significance at $P \leq 0.001$

between the delay of phrenic nerve DML and the severity of cervical spondylosis.

We recommend further investigation in the form of MRI of the cervical region to all patients, diaphragmatic EMG in patients with lower amplitudes of phrenic CMAP, and neuromuscular ultrasound to evaluate the phrenic nerve.

\section{Study limitations}

The limitation of the current study is the small sample size to be done on a larger scale for more accurate results. We recommend further investigations in the form of MRI of the cervical region to all patients, diaphragmatic EMG in patients with lower amplitudes of phrenic CMAP, and neuromuscular ultrasound for the phrenic nerve.

\section{Abbreviations}

AUC: Area under the curve; CMAP: Compound motor action potential; DML: Distal motor latency; DP: Diaphragmatic paralysis;

EMG: Electromyography; MRI: Magnetic resonance imaging; NCS: Nerve conduction study; ROC: Receiver operating characteristic

\section{Acknowledgements}

To all patients included in this study for their cooperation, also the department's nurses and workers who assisted in the conduction study processing.

\section{Authors' contributions}

$\mathrm{RH}$ analyzed and interpreted the patient data regarding their cervical spondylosis and neurological examination. SG performed the neurological examination of the upper and lower limbs and was a major contributor in writing the manuscript. MF was involved in the data collection and shared in writing the manuscript. All authors read and approved the final manuscript All authors were involved in the concept, design, data collection, analysis, and drafting of the manuscript.

\section{Funding}

This research did not receive any specific grant from funding agencies in the public, commercial, or non-profit sectors.

\section{Availability of data and materials}

The data of the current study are available from the corresponding author on reasonable request.

\section{Ethics approval and consent to participate}

All participants signed a written consent to participate in the study. The study was approved by the Faculty of Medicine, Ain Shams University research ethics committee with a reference number: FWA 000017585 . The Faculty of Medicine, Ain Shams University research ethics committee FMASU REC is organized and operated according to the guidelines of the International Council on Harmonization (ICH) Anesthesiology and the Islamic Organization for Medical Sciences (IOMS), the United States Office for Human Research Protections, and the United States Code of Federal Regulations and operates under Wide Federal Assurance No. FWA 000017585.

\section{Consent for publication}

All patients included in this research gave written informed consent to publish the data contained within this study.

The authors declare that this paper was not published anywhere.

\section{Competing interests}

The authors declare no conflict of interest.

Received: 12 October 2020 Accepted: 27 November 2020

Published online: 09 January 2021

\section{References}

1. Banneheka S (2008) Morphological study of the ansa cervicalis and the phrenic nerve. Anat Sci Int 83:31-44

2. McCool FD, Tzelepis GE (2012) Dysfunction of the d7iaphragm. N Engl J Med 366:932-942

3. Shedid D, Benzel EC (2007) Cervical spondylosis anatomy: Pathophysiology and biomechanics. Neurosurgery. 60:7-13

4. Kalsi-Ryan S, Karadimas S, Fehlings M (2013) Cervical spondylotic myelopathy: the clinical phenomenon and the current pathobiology of an increasingly prevalent and devastating disorder. Neuroscientist. 19:409-421

5. Houston JG, Angus RM, Cowan MD, McMillan NC, Thomson NC (1994) Ultrasound assessment of normal hemidiaphragmatic movement: relation to inspiratory volume. Thorax. 49:500-503

6. Ofiram E, Garvey T, Schwender J, Schwender J, Joseph F, Transfeld E et al (2009) Cervical degenerative index: a new quantitative radiographic scoring system for cervical spondylosis with interobserver intraobserver reliability testing. J Orthop Traumatol 10:21-26

7. Resman-Gaspersc A, Podnar S (2008) Phrenic nerve conductions Studies: technical aspects and normative data. Muscle Nerve 37:36-41

8. Gibson GJ (1989) Diaphragmatic paresis: pathophysiology, clinical features, and investigation. Thorax. 44:960-970

9. Hart N, Nickol AH, Cramer D, Ward SP, Lofaso F, Pride NB et al (2002) Effect of severe isolated unilateral and bilateral diaphragm weakness on exercise performance. Am J Respir Crit Care Med 165:1265-1270

10. Sagliocco L, Orlandi G, Calabrese R, Pellegrinetti A, Baglini O, Castelli F et al (2003) Electrodiagnostic evidence of phrenic nerve demyelination in Charcot-Marie Tooth disease 1A. Am J Phys Med Rehabil 82:754-759

11. Meenakshi G, Saurabh G, Sushma S, Mohita S (2019) The role of motor nerve conduction: in cervical radiculopathy patients. Int J Res Med Sci 7:1-4

12. Hiroaki M, Toshinori S, Fumitake T, Kazuta Y, Yoichiro T, Takashi C et al (2019) Hemidiaphragmatic paralysis due to cervical spondylosis: a case report. Spine Surg Relat Res 3:183-187

13. Sachin P, Aditi K, Vinod S, Satish W (2013) The study of diagnostic efficacy of nerve conduction study parameters in cervical radiculopathy. Clin Diagn Res J 7:2680-2682

14. Tracy JA, Bartleson JD (2010) Cervical spondylotic myelopathy. Neurologist. 16(3):176-187

\section{Publisher's Note}

Springer Nature remains neutral with regard to jurisdictional claims in published maps and institutional affiliations. 